\title{
pH-Responsive Amphiphilic Polyether Micelles with Superior Stability for Smart Drug Delivery
}

Iloh Son, ${ }^{1}$ Yujin Lee, ${ }^{2}$ Jinsu Baek, ${ }^{1}$ Miran Park, ${ }^{2}$ Daeho Han, ${ }^{3}$ Seung Kyu Min, ${ }^{3}$ Dongwon Lee, ${ }^{2}$ and Byeong-Su Kim ${ }^{l} *$

${ }^{1}$ Department of Chemistry, Yonsei University, Seoul 03722, Republic of Korea

${ }^{2}$ Department of PolymerNano Science and Technology, Chonbuk National University, Jeonju 54896, Republic of Korea

${ }^{3}$ Department of Chemistry, Ulsan National Institute of Science and Technology (UNIST), Ulsan 44919, Republic of Korea

E-mail: bskim19@yonsei.ac.kr (B.-S.K.) 
Supporting Information<smiles>CC(OCC1CO1)OC1=CC[IH]CC1</smiles>

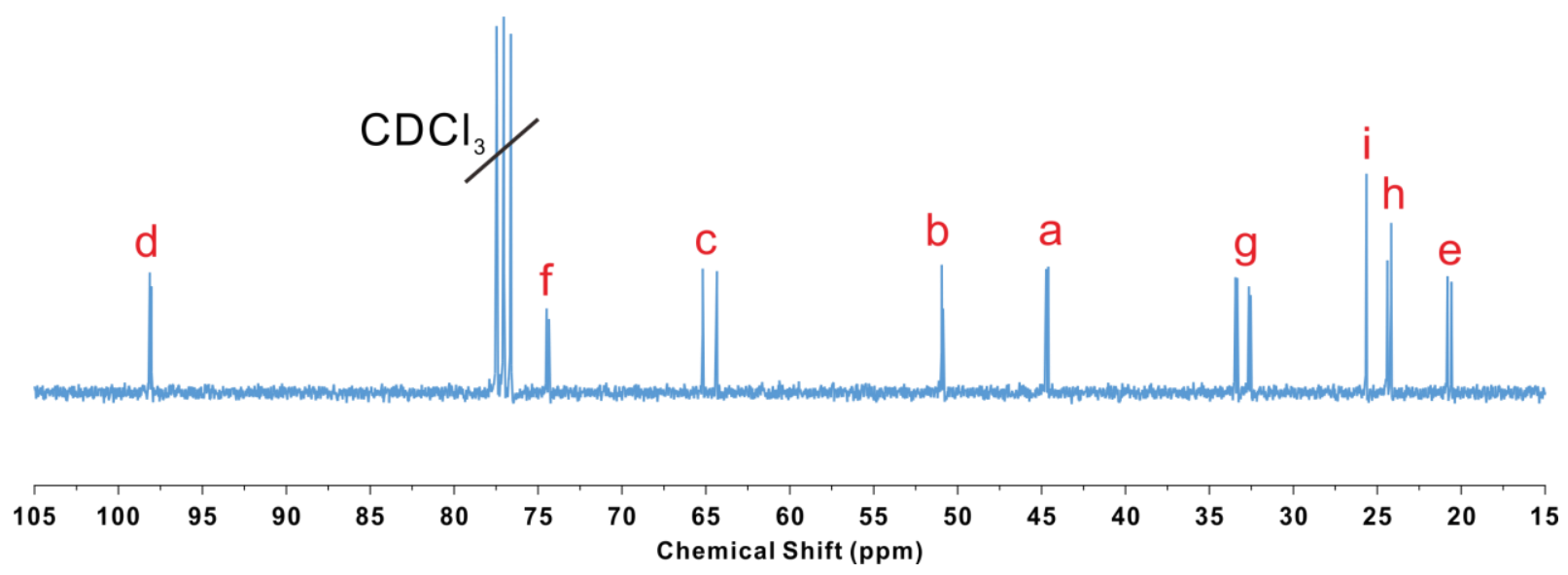

Figure S1. ${ }^{13} \mathrm{C}$ NMR spectrum of CHGE $\left(100 \mathrm{MHz}, \mathrm{CDCl}_{3}\right)$. 
Supporting Information<smiles>[CH]C(OCC1O[C@@H]1I)OC1=CCCI([18OH])CC1</smiles>

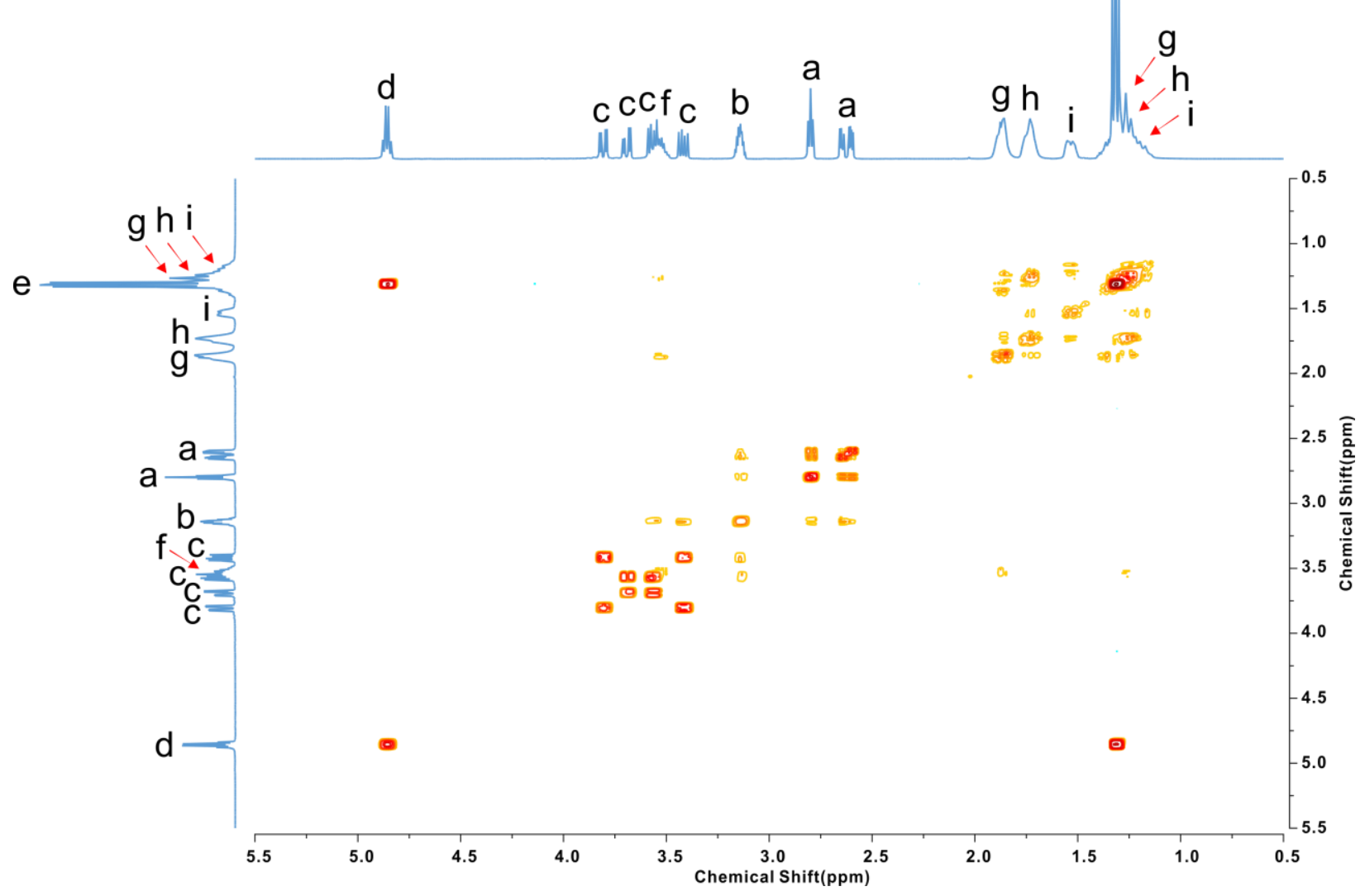

Figure S2. ${ }^{1} \mathrm{H}-{ }^{1} \mathrm{H}$ correlation spectroscopy (COSY) spectrum of $\mathrm{CHGE}$ in $\mathrm{CDCl}_{3}$. 

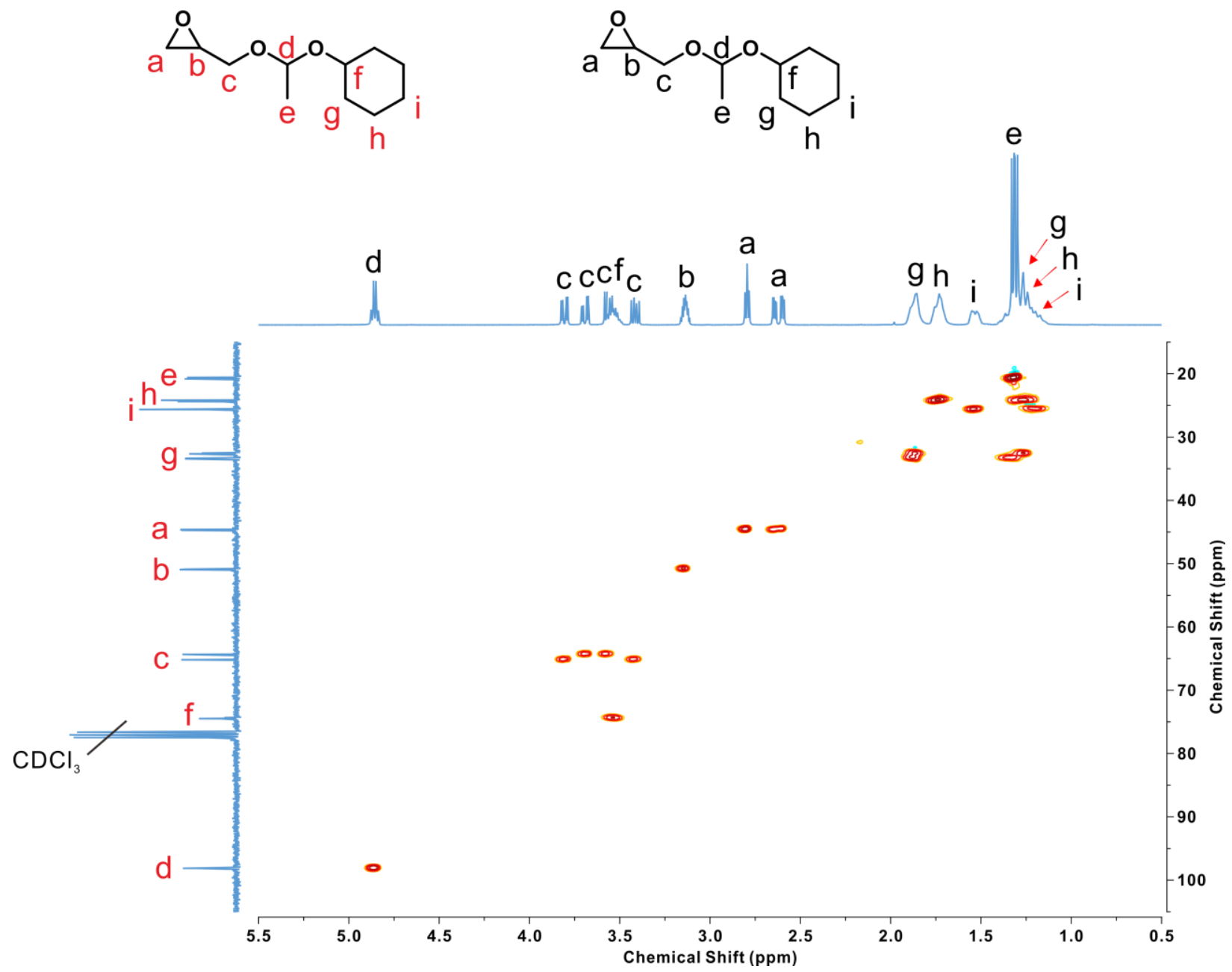

Figure S3. ${ }^{1} \mathrm{H}-{ }^{13} \mathrm{C}$ Heteronuclear single quantum coherence (HSQC) spectroscopy spectrum of CHGE in $\mathrm{CDCl}_{3}$. 
Supporting Information

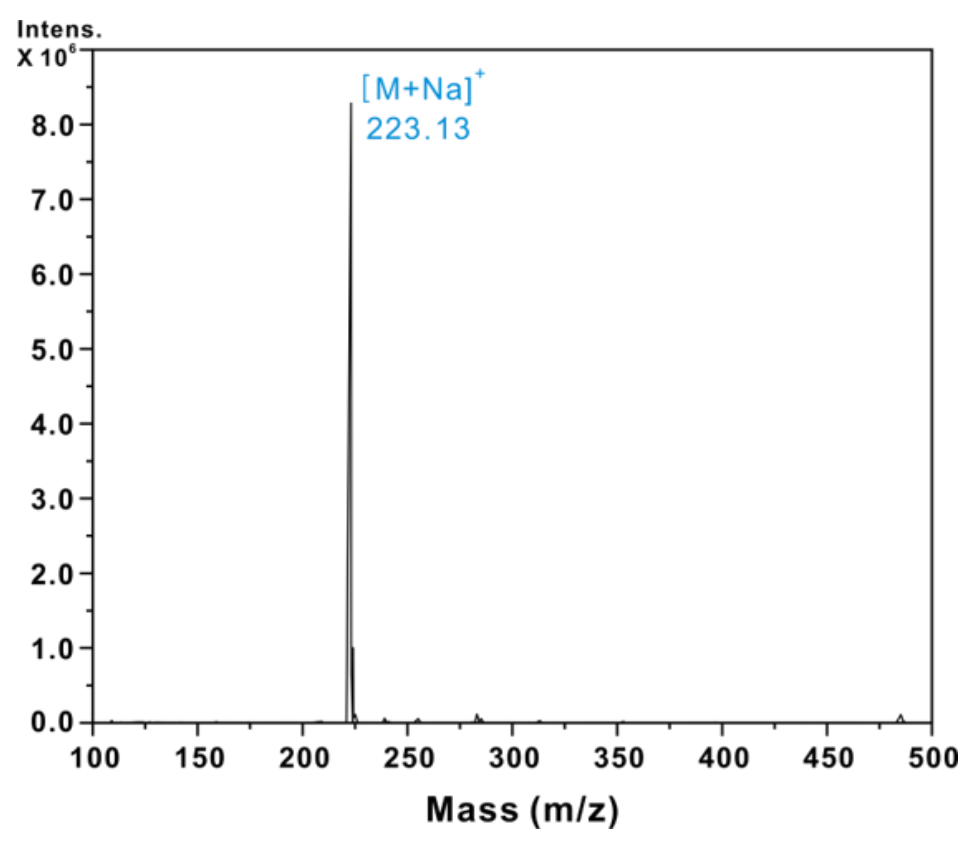

Figure S4. ESI-MS spectrum of CHGE. The exact mass of CHGE corresponds to $200.14 \mathrm{~g} / \mathrm{mol}$. 


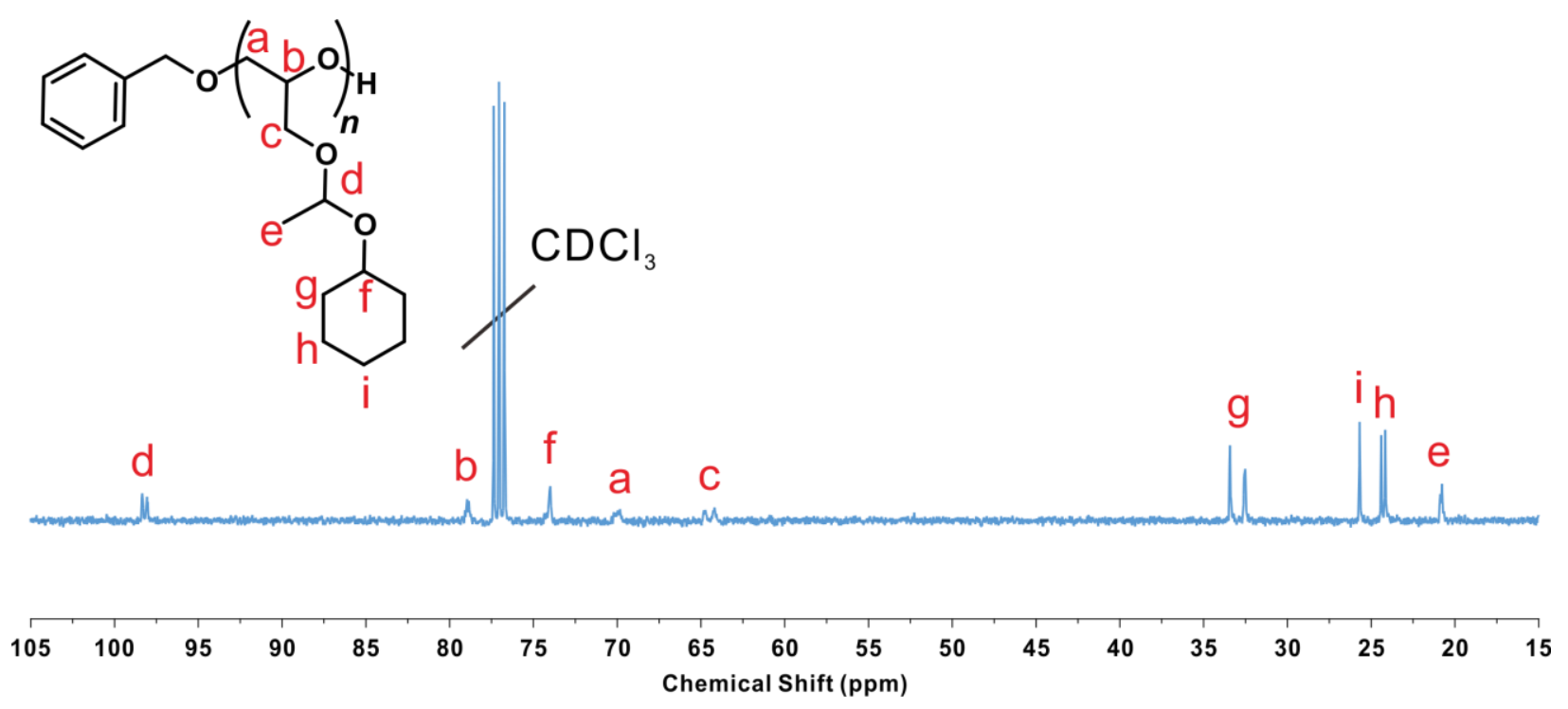

Figure S5. ${ }^{13} \mathrm{C}$ NMR spectrum of PCHGE homopolymer $\left(\mathrm{PCHGE}_{50}\right.$ in Table 1) (100 MHz, $\left.\mathrm{CDCl}_{3}\right)$. 


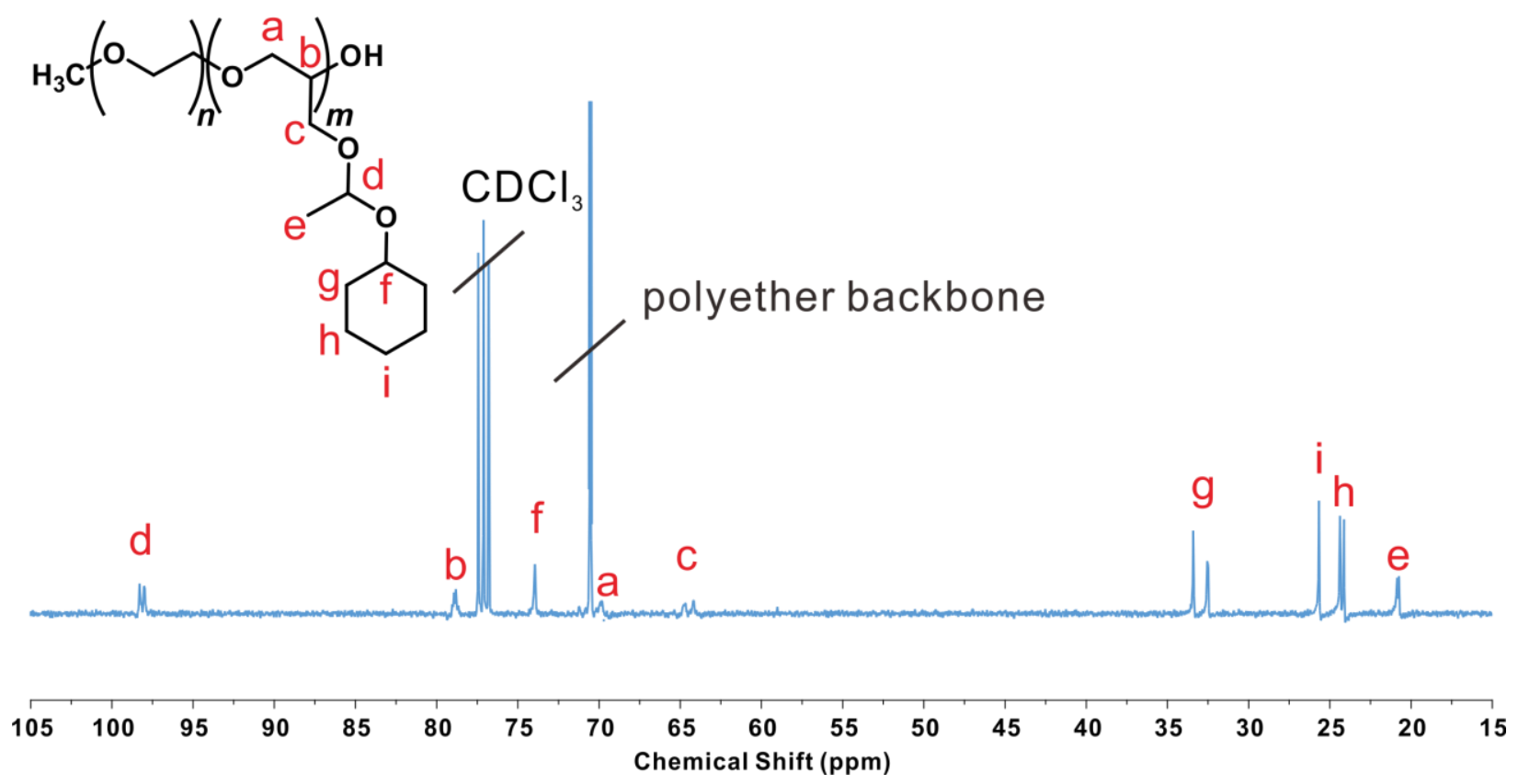

Figure S6. ${ }^{13} \mathrm{C}$ NMR spectrum of $m$ PEG- $b$-PCHGE block copolymer (CH45 in Table 1) (100 $\left.\mathrm{MHz}, \mathrm{CDCl}_{3}\right)$. 
Supporting Information

a

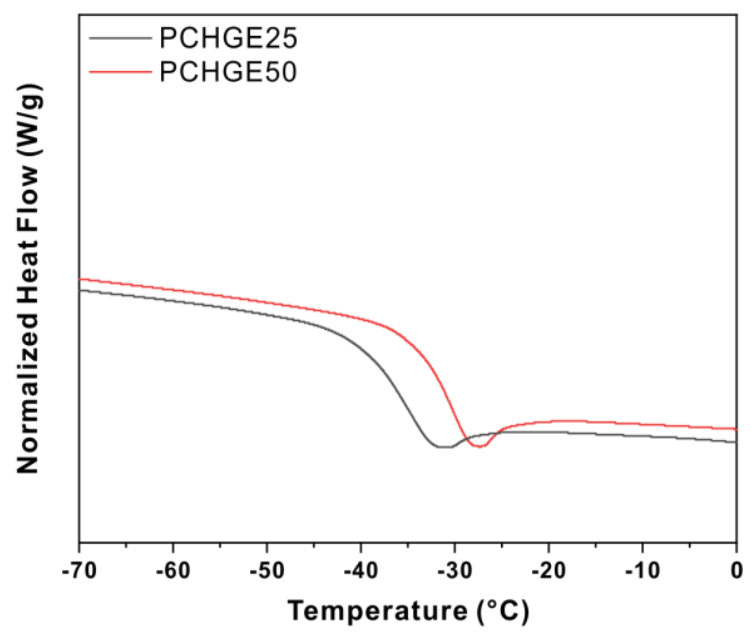

b
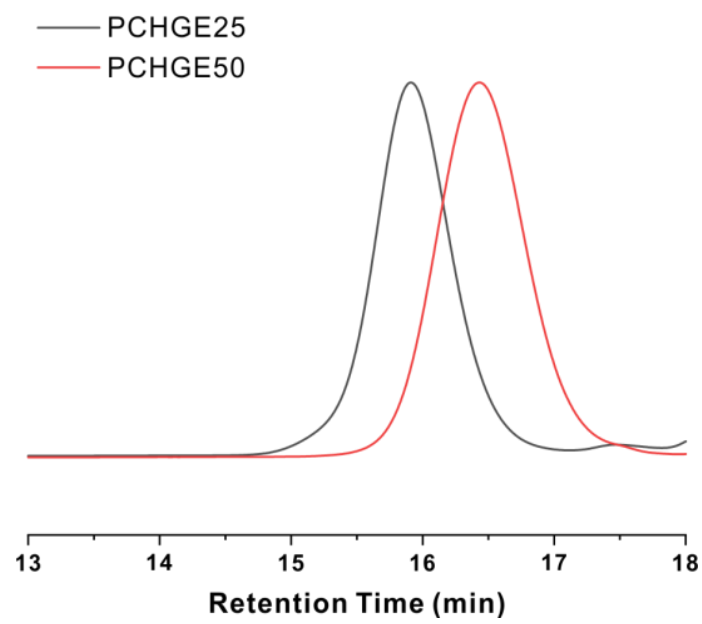

Figure S7. (a) DSC thermograms and (b) GPC elution traces of PCHGE homopolymers. (black) $\mathrm{PCHGE}_{25}$ and (red) $\mathrm{PCHGE}_{50}$. 

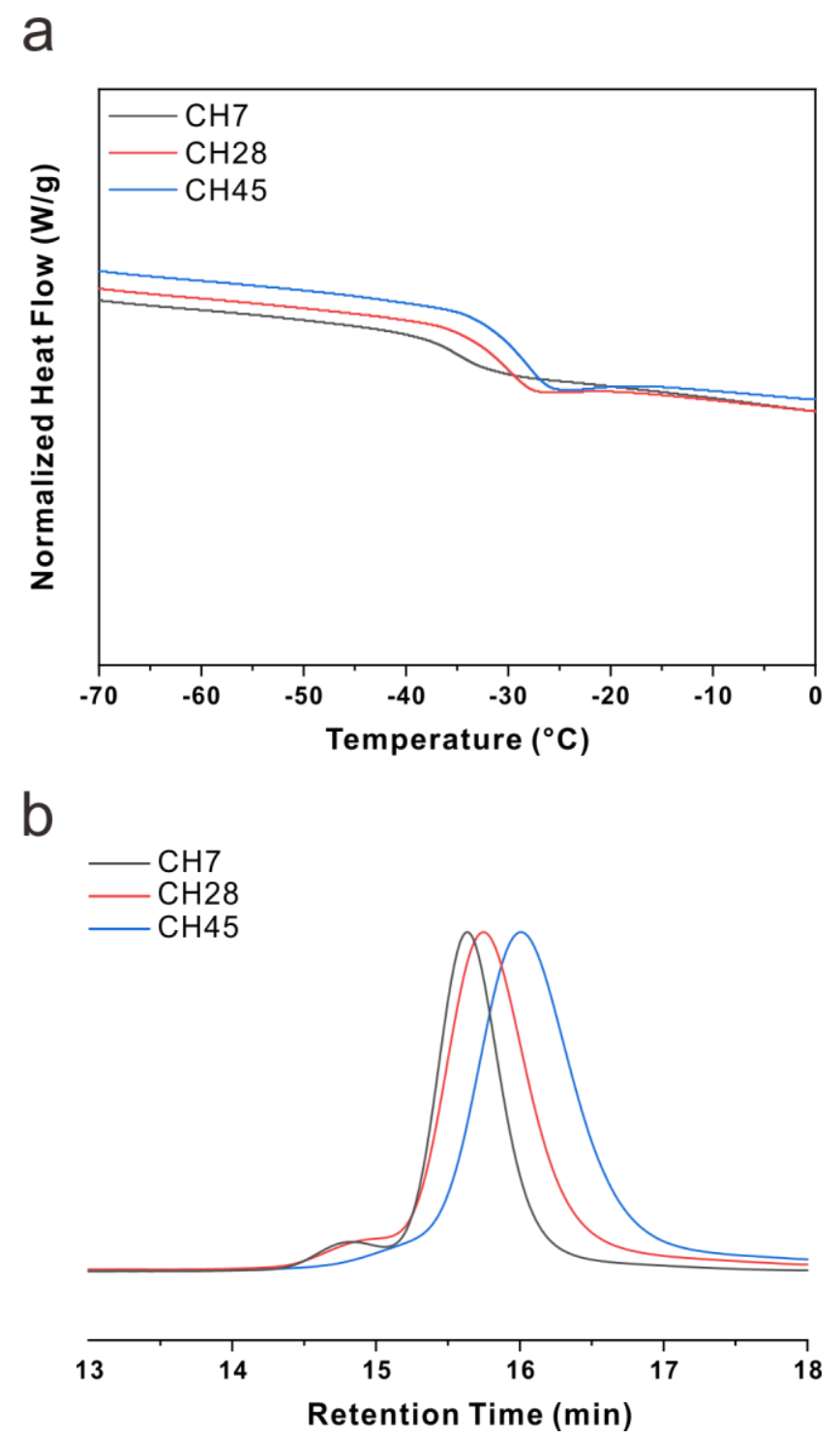

Figure S8. (a) DSC thermograms and (b) GPC elution traces of $m$ PEG- $b$-PCHGE block copolymers (CH7, $\mathrm{CH} 28$, and $\mathrm{CH} 45$ in Table 1). 


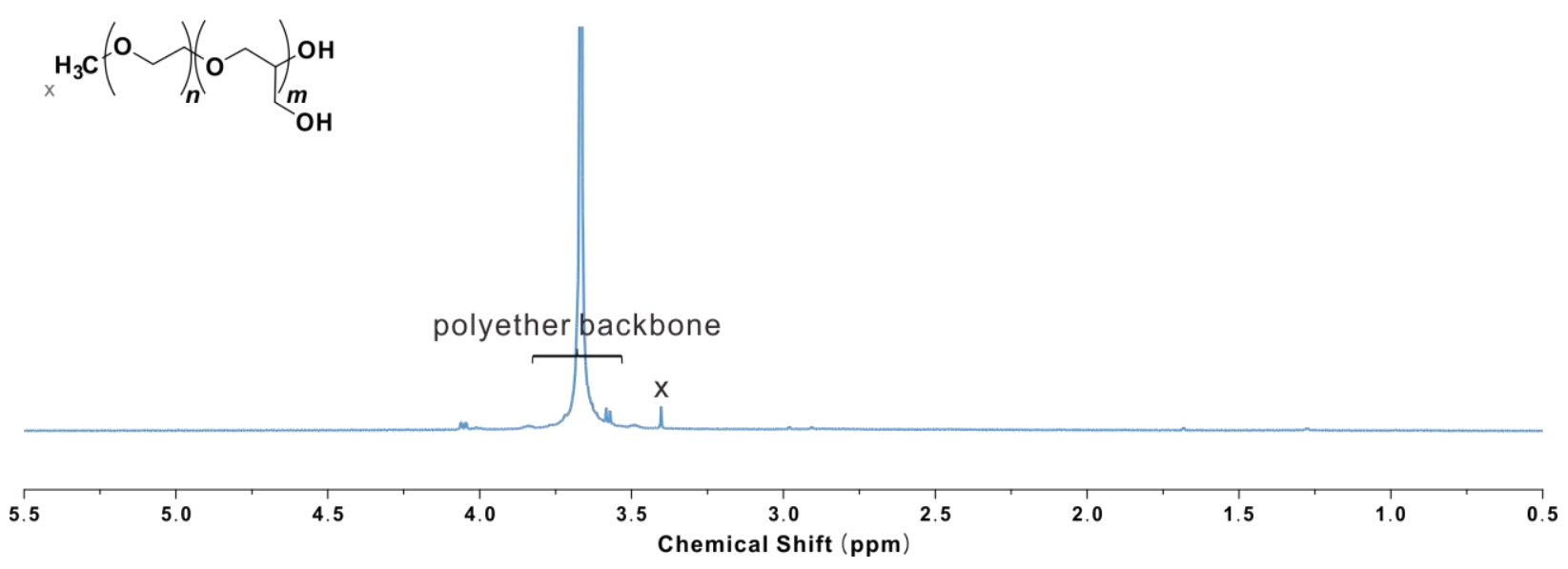

Figure S9. ${ }^{1} \mathrm{H}$ NMR spectra of the product of acidic deprotection of hydrophobic block copolymer (CH45 in Table 1) (400 MHz, $\left.\mathrm{CDCl}_{3}\right)$. 
Supporting Information

a

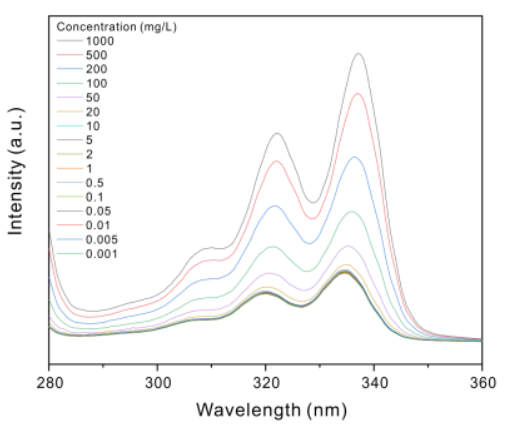

b

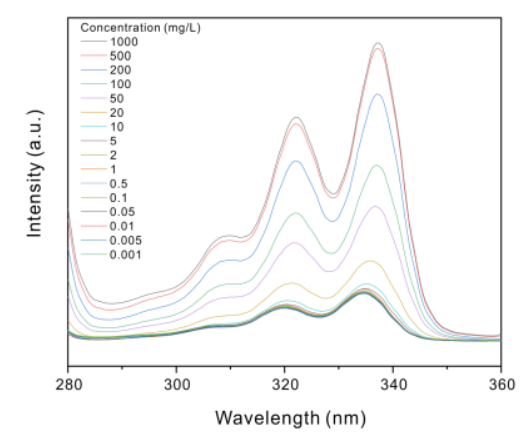

C

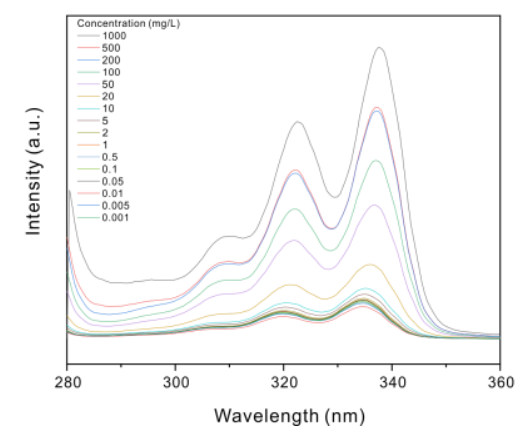

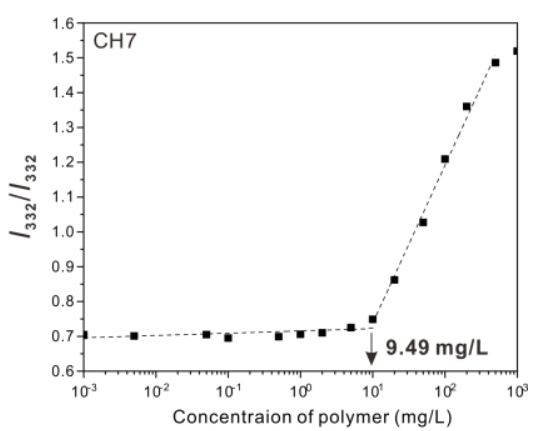
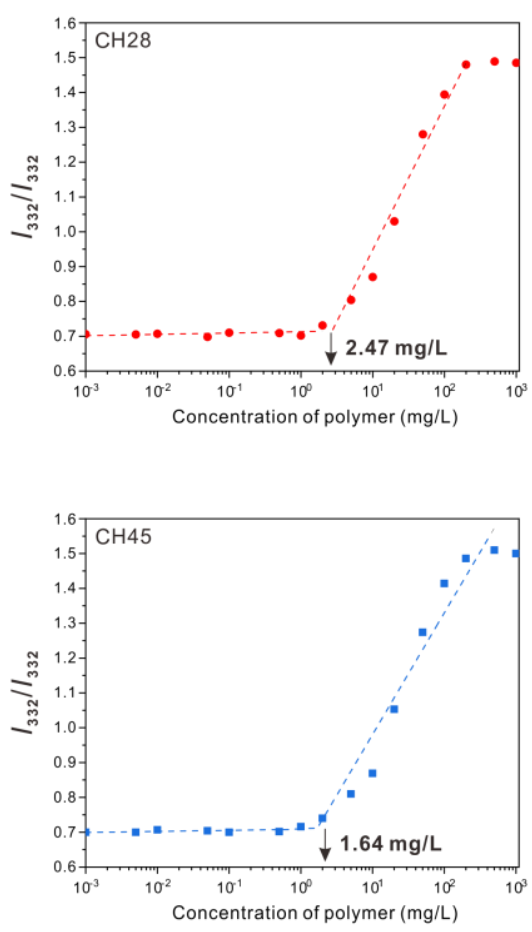

Figure S10. Excitation spectra of pyrene with various concentration of (a) $\mathrm{CH} 7$, (b) $\mathrm{CH} 28$, and (c) CH45 block copolymer and determination of CMC values via plotting $I_{339} / I_{332}$ as a function of polymer concentration using the excitation spectra of pyrene (emission wavelength of $372 \mathrm{~nm}$ ). 
Supporting Information

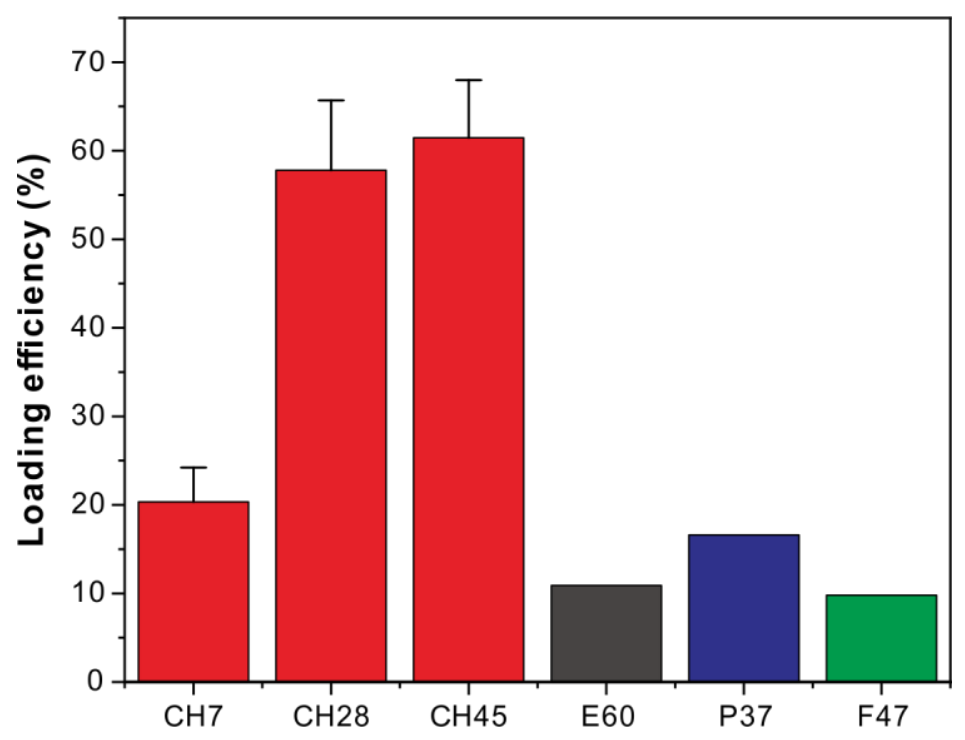

Figure S11. Encapsulation efficiency of Nile Red in a series of $\mathrm{CH}$ micelles in reference to E, P, and F series micelles.

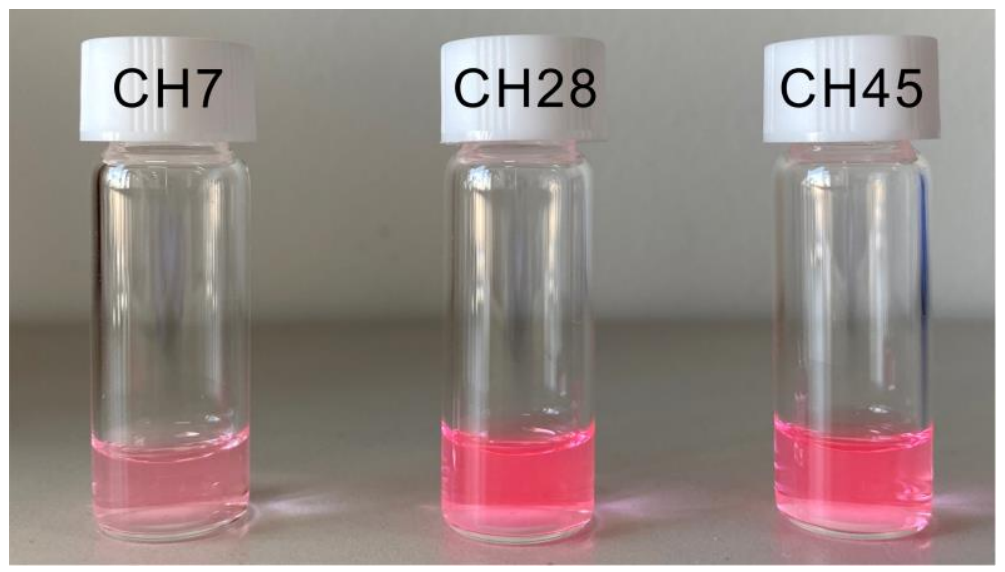

Figure S12. Photographic image of the micelles containing Nile Red in $\mathrm{CH} 7, \mathrm{CH} 28$, and $\mathrm{CH} 45$. 

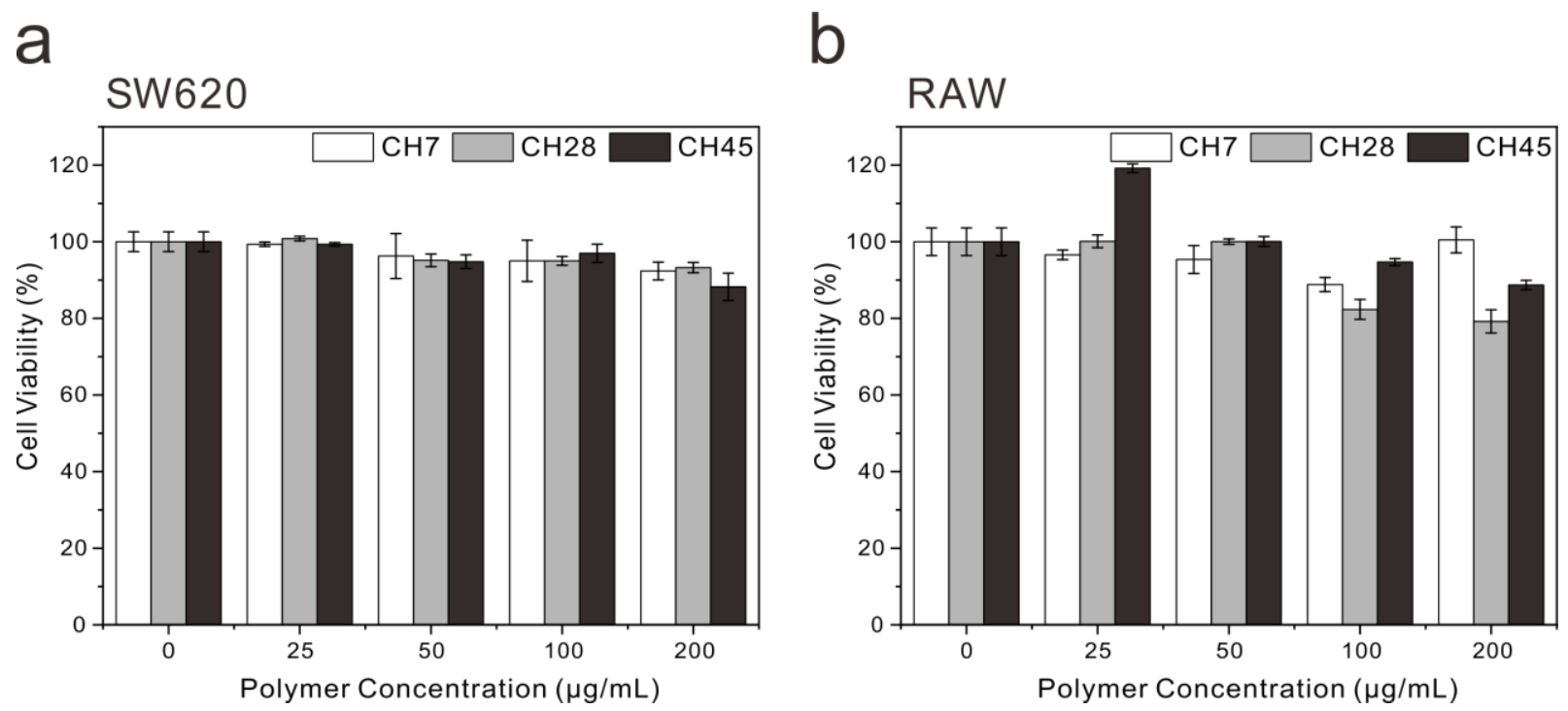

Figure S13. In vitro cell viability assay of $\mathrm{CH}$ micelles determined by the MTT assay using (a) SW620 cells and (b) RAW cells.

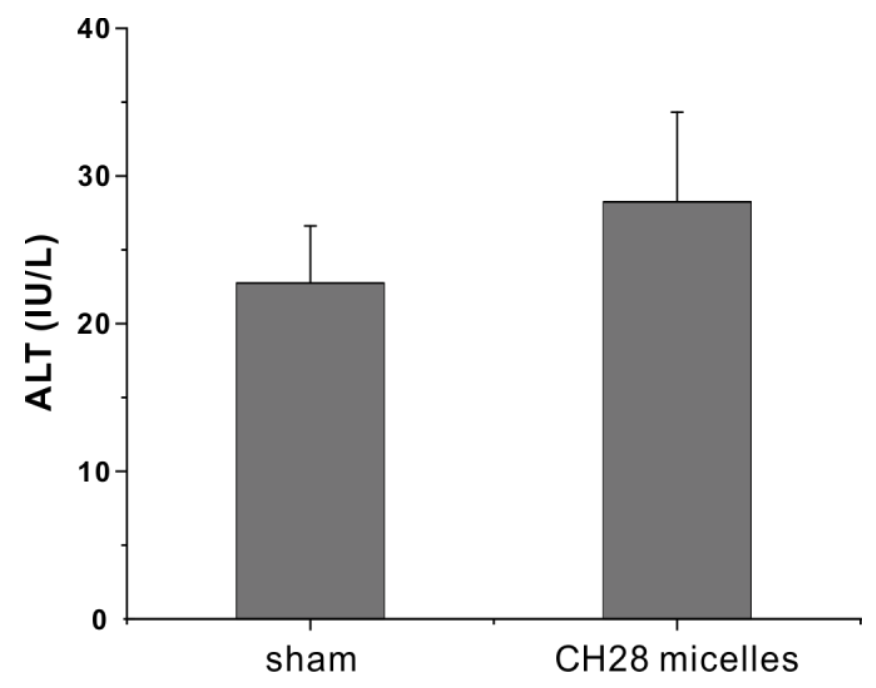

Figure S14. In vivo toxicity assay of $\mathrm{CH} 28$ micelles determined by the alanine transaminase (ALT) assay. The level of ALT does not show significant difference with sham, suggesting no liver damages in mouse models. 